\title{
Polarisation Control Mechanism of DFB Fibre Lasers
}

Varming, Poul; Philipsen, Jacob Lundgreen; Berendt, Martin Ole; Lauridsen, Vibeke Claudia; Povlsen, Jørn Hedegaard; Hübner, Jörg; Kristensen, M.; Palsdottir, B.

Published in:

Lasers and Electro-Optics Europe, 1998. 1998 CLEO/Europe. Conference on

Publication date:

1998

Document Version

Publisher's PDF, also known as Version of record

Link back to DTU Orbit

Citation (APA):

Varming, P., Philipsen, J. L., Berendt, M. O., Lauridsen, V. C., Povlsen, J. H., Hübner, J., Kristensen, M., \& Palsdottir, B. (1998). Polarisation Control Mechanism of DFB Fibre Lasers. In Lasers and Electro-Optics Europe, 1998. 1998 CLEO/Europe. Conference on IEEE.

\section{General rights}

Copyright and moral rights for the publications made accessible in the public portal are retained by the authors and/or other copyright owners and it is a condition of accessing publications that users recognise and abide by the legal requirements associated with these rights.

- Users may download and print one copy of any publication from the public portal for the purpose of private study or research.

- You may not further distribute the material or use it for any profit-making activity or commercial gain

- You may freely distribute the URL identifying the publication in the public portal 
12.15 CTuF6

Single-polarisation operation of injection locked fibre DFB lasers Shinji Yamashita and Gregory J. Cowle

Optoelectronics Research Centre, University of Sonthampton. Soutlampton SO17 1BJ, UK

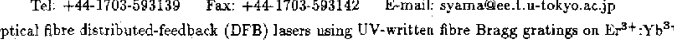
fibres feature single-frequescy operation, thus are a promisiag teechuology for applications in optical fibre communications[1]. Most fibre DFB lasers, however, actually. operate in two orthogonal polarisation applications. In this paper, we report single-polarisation operations of fibre DFB lasers using injection locking technigues, which are similar to those used for polarisation switching in He-Ne lasers $[2]$.

The configuration of the injection locked fibre DFB laser is shown in Fig.1. The fibre DFB laser is pumped witk: a $980 \mathrm{~nm}$ pump laser diode (I.D) through a WDM ecupler, and the lasing light is outprot through the WDM coupler and an isclator. A single-frequency $\left(f_{i}\right)$, single-polarisation signal from tunatle LD is fed to anolter end of the DFE laser through a polatisation controller (PC) and an isolator.

dive

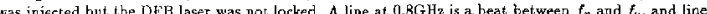
at $0.5 G \mathrm{~F}_{z}$ and $0.9 \mathrm{GHz} z$ are beats between $f_{i}$ and $f_{f}$ and between $f_{i}$ and $f_{y}$, respectively. When $f_{i}$ was set closer to $f_{x}$, the DFB lascr was injection locked, i.c. $f_{x}$ was locked to $f_{i}$, and the beats between $f_{w}$ and $f_{s}$ and between $f_{i}$ and $f_{y}$ disappeared, as shown in Fig? $($ b) $)$, which means that the $y$-polarisation was suppressed by injection locking. We confirmed using a polarisation analyzer that, when $f_{x}$ was locked to $f_{1}$. the cutput was in $x$-polsrisations, regardless of the polarisation state of injected light, That was also true when $f_{y}$ was locked to $f_{i}$. The injection locking rauge was found to be around $10 \mathrm{MHz}$ at the injection power of $0.2 \mathrm{~mW}$, which is very narrow compared with that of DFB LDs (typically a fow GHz), frequency stability of injected lightr, the locking betavior was uristable. Irequency stability of injected light, the locking betavior was unstable.
As a sirtipler and more siable method to achieve single-polarisation operation, we tried the solfinjection locking techaique, in which one of two polarisation is feed back to the DFB laser, as shown in Fiz. 3 . A polarizer and a mirror are used, and two PCs are inserted between the DFB laser and the the two polarisations to be locked by adjusting the $\mathrm{PCl}$

Figure 4 showa the R.F spectra obtained by heterodyne detection of the laser outpuc with a light from the tunable. LD. Without self-injection, two beai lines were observed corresponding to $f_{x}$ and $f_{y}$ separated by $0.8\left(\mathrm{HH}_{z}\right.$, as shown in Fig.d(a). With self-injechion, only $f=$ was locked and $f_{y}$ was suppressed

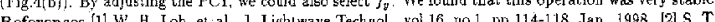
Hentow, et al., Opt. Lett., vol. $\bar{T}$, no 8, po.356-358, Aus. 1982

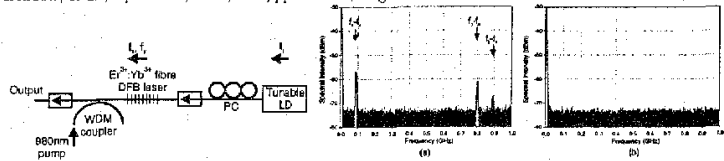

Fig.1 Injection locked fibre DFB laser. Fig. 2 RF spectra. (a) Unlocked (b) locked $\left(f_{i}=f_{*}\right)$



Fig 3 Self-injection locked fibre DFB laser. Fis.4 RF test spertra. (a) No injection (b) locked to $t$

\subsection{CTuF7}

Polarisation control mechanism of DFB fibre lasers

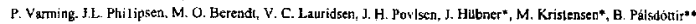

Department of Ekctromagnetic Systems, Technical University of Denmark, Building 348. DK.28(0) Lyngb), Denrnark

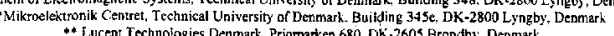

Since the introduction of single-mode DFB fibre lasers with UV induced plase-shift, these lasers have found many applications within optical communication [1]. Single polarisation operation of the laser coutd be attributed to a polarisation dependence of either the grating reflectivity, background loss, erbium gain, or the phase-shift. lt has been shown that a bieffringent distributed phase-shift causes a considerable difference in the magnitule of the prase-shint experienced by the hwo polarisations [2]. However, unts now it has nor been


A Bragg grating was written in an erbium doped fibre using a KrF exciner laser. The UV induced bitefectingen was around $210^{3}$. A distributed phase-shift was induced by exposing the centre part of the Bragg erating io additional UV pulses through a $4 \mathrm{~mm}$ aperture. After 1500 pulses of this UV post-processing (UVPP), single polarisation lasing was obtaised when the Bragg grating was pumped by a diode laser. Continuing the UVPP, the lasing was shifed three times berween orthogonal polarisation states as shown in Fig. I. The reversible behayiou indicates that the lasing polarisation made is not controiled by a polarisation dependent loss Fabry-Perot interferometer. The lasing polasisation modes wore rebad to the transmission peaks in scanning grating caused by the phase-shift. The phase-shift is polarisation dependent and the difference is controlled by the birefringence of the UV-induced index change. An index change of $210^{-1}$ in the $4 \mathrm{~mm}$ phasc-shift region is required for obraining a gratimg phase-shit of $\pi$. Throughout the UVPP we obsezved excellent agreemen between the position of the transmission peaks and the power of the corresponding lasing polarisation modes. Single polarisation Bragg grating.

the polarisation of a single-mode DFB fibre laser can be controlled by

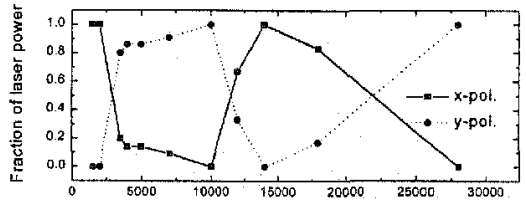

Number of UV pulses in post-processing

Figure 1: Evelution of the fraction of power in the $x$ - ard $y$-polarisation duting UV post-processing

[1] J. Hübner, P. Varming and M. Kristensen, "Five vavelength DFB ribre laser source for WDM systems", Electronics Letters, Volume 33, Number 2, Pages 139-140,1997.

[2] H. Storay, B. Sahlgren and R. Stubbe, "Single polarisation fibre DFB laser", Electranics Letters, Volune 33, Number l. Pages $56-57,1997$. 